\title{
Correction to: Benchmarking different brands of silicone oils
}

\section{Joachim H. Dresp ${ }^{1}$ (D)}

Published online: 5 August 2020

(C) Springer-Verlag GmbH Germany, part of Springer Nature 2020

\section{Correction to: Graefe's Archive for Clinical and Experimental Ophthalmology https://doi.org/10.1007/s00417-020-04809-2}

The orignal publication of this paper contains error in the PDF version of Table 2 for the "Median" was missing. Please see below corrected Table 2 .

The original article has been corrected.

Publisher's note Springer Nature remains neutral with regard to jurisdictional claims in published maps and institutional affiliations.

The online version of the original article can be found at https://doi.org/ $10.1007 / \mathrm{s} 00417-020-04809-2$

Joachim H. Dresp

1 Munich, Germany 


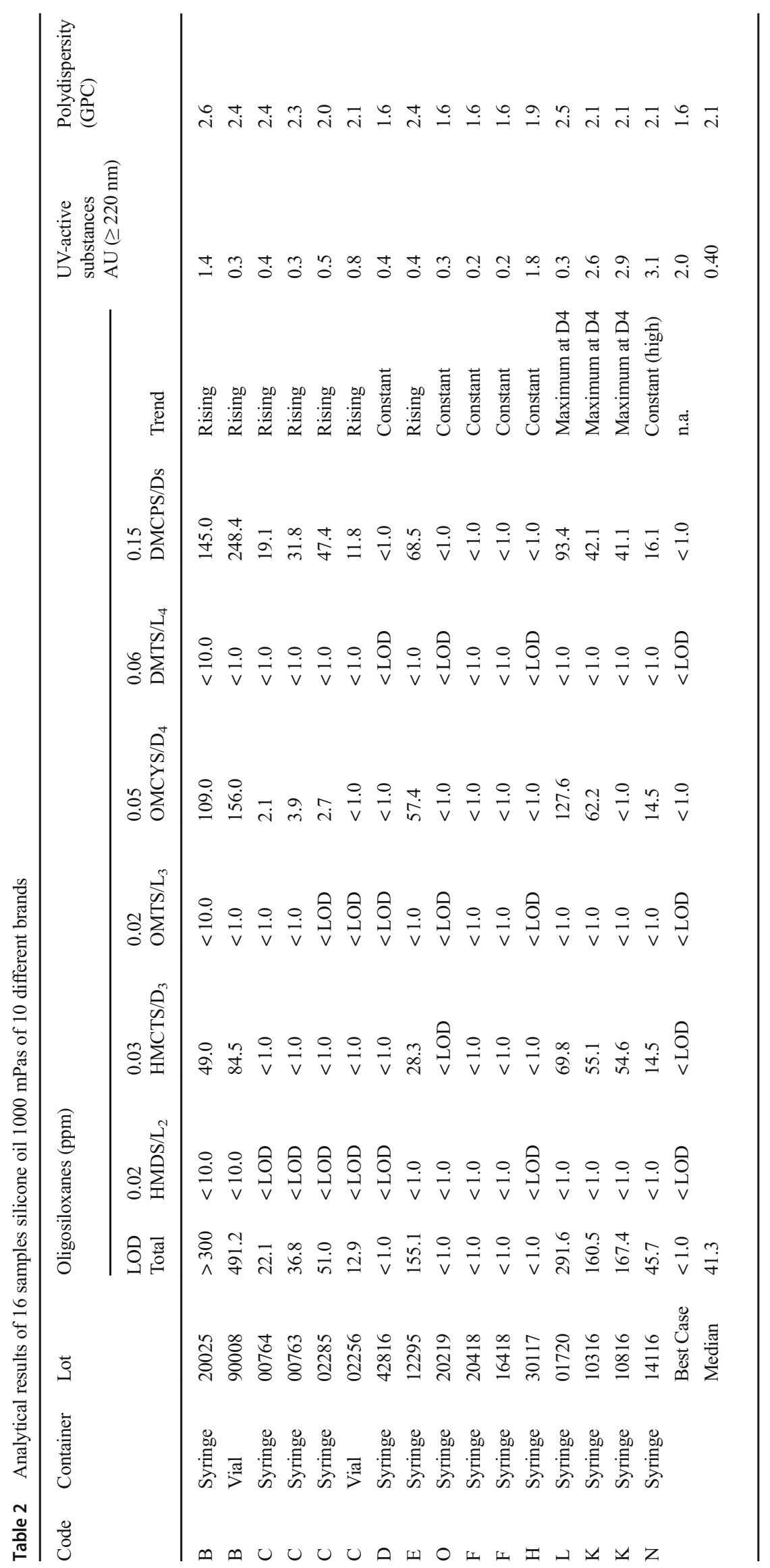

